\title{
Article \\ Enzymatic Activity and Microbial Diversity of Sod-Podzolic Soil Microbiota Using 16S rRNA Amplicon Sequencing following Antibiotic Exposure
}

\author{
Tatiana Trifonova ${ }^{1,2, *}$, Anastasia Kosmacheva ${ }^{2}\left(\mathbb{D}\right.$, Alexander Sprygin ${ }^{3}\left(\mathbb{D}\right.$, Svetlana Chesnokova $^{2}$ \\ and Olga Byadovskaya ${ }^{3}$ (D) \\ 1 Department of Soil Geography, M.V. Lomonosov Moscow State University, Moscow 119991, Russia \\ 2 Department of Biology and Ecology, Vladimir State University Named after Alexander and Nikolay Stoletovs, \\ Vladimir 600000, Russia; hijadelaluna@mail.ru (A.K.); chesnokova.chemist@mail.ru (S.C.) \\ 3 FGBI “Federal Centre for Animal Health" (FGBI “ARRIAH”), Vladimir 600901, Russia; \\ spriginav@mail.ru (A.S.); bjadovskaya@arriah.ru (O.B.) \\ * Correspondence: tatrifon@mail.ru; Tel.: +7-910-771-2442
}

check for updates

Citation: Trifonova, T.; Kosmacheva, A.; Sprygin, A.; Chesnokova, S.; Byadovskaya, O. Enzymatic Activity and Microbial Diversity of Sod-Podzolic Soil Microbiota Using 16S rRNA Amplicon Sequencing following Antibiotic Exposure. Antibiotics 2021, 10, 970. https:// doi.org/10.3390/antibiotics10080970

Academic Editor: Marc Maresca

Received: 20 May 2021

Accepted: 9 August 2021

Published: 12 August 2021

Publisher's Note: MDPI stays neutral with regard to jurisdictional claims in published maps and institutional affiliations.

Copyright: (c) 2021 by the authors. Licensee MDPI, Basel, Switzerland. This article is an open access article distributed under the terms and conditions of the Creative Commons Attribution (CC BY) license (https:/ / creativecommons.org/licenses/by/ $4.0 /)$.

\begin{abstract}
Antibiotic contamination of the environment negatively affects soil fertility by disrupting natural microbial communities. Currently, the study of the effect of antibacterial drugs on soils typical in Russia, which are of great importance for agriculture, is insufficient. Despite a rapid increase in the number of metagenomic studies, this article is the first publication devoted to the microbial diversity of sod-podzolic soil and its relationship with enzymatic activity. In the present study, we use 16S rRNA metagenomic sequencing to analyze microbiota dynamics and to examine soil enzymatic activities after antibiotic treatment with benzylpenicillin, oxytetracycline, and tylosin. We found that, following treatment, urease activity was reduced regardless of the antibiotic used while nitrification activity showed no statistically significant changes $(p>0.05)$. Oxytetracycline and tylosin produced no effect on catalase activity but benzylpenicillin caused an increase. Benzylpenicillin and oxytetracycline increased cellulolytic activity whereas tylosin had no significant effect $(p>0.05)$. Microbiome profiling through 16S rRNA gene sequencing demonstrated antibiotic administration and exhibited no significant impact on bacterial abundance and species diversity $(p>0.05)$, thus pointing to the resilience of the soil microbial community. Oxytetracycline, benzylpenicillin, and tylosin are likely to negatively affect the enzymatic profiles in sod-podzolic soil but with a negligible influence on the bacterial composition.
\end{abstract}

Keywords: benzylpenicillin; oxytetracycline; tylosin; microbiome; bacterial community

\section{Introduction}

Animal husbandry intensification is associated not only with a rise in economic indicators but also with a number of negative impacts on the environment such as the use of medicines against animal infectious diseases, including various spectrum antibiotics. The antibacterial drugs introduced are mainly excreted from the animal body with metabolic products, which are partially used for fertilizing agricultural land and greenhouses [1-5]. Thus, the antimicrobials introduced into the environment threaten natural microbial communities due to their ability to affect soil microorganisms, to change the total biomass, to affect the relative number of different groups, and to change soil enzyme activity. As a result, soil fertility suffers. In this regard, the study of antibiotics as soil ecosystem pollutants has garnered considerable attention. The assessment of enzymatic activity changes and microbial diversity using metagenomics or $16 S$ rRNA gene sequencing under the impact of antibiotic drugs provides significant diagnostic indicators in such research [6-16].

A number of the published studies have been devoted to the impact of antibiotics on soil enzymatic activity changes [5,7-13]. A urease activity change was detected for oxytetracycline introduction, thus affecting the nitrogen availability in soil [9]. The exposure to 
different dosages of tylosin, benzylpenicillin, and oxytetracycline caused catalase activity changes in ordinary chernozem, brown forest, and dark chestnut soils depending on both the soil type and the drug properties and concentrations [11-13]. The stimulating and inhibitory effects of tylosin, ampicillin, oxytetracycline, and benzylpenicillin $(50-700 \mathrm{mg} / \mathrm{kg}$ ) on the nitrification, urease, catalase, and cellulolytic activities of various soil types in model laboratory experiments have been described in several published studies [17-20].

The antibiotic ability to cause both enzyme activity decrease and increase is usually associated with changes in the bacterial community number and diversity. However, this issue is poorly studied nowadays, thus complicating our comprehension of the reasons for fertile soil changes in response to anthropogenic pressure [7,14-16]. Oxytetracycline introduction has caused diversity changes in the soil microbiota, pig manure, and wheat straw [14,15]. The effect of $2000 \mathrm{mcg} / \mathrm{g}$ tylosin demonstrated a temporary change in the structure of the soil bacterial community and a tendency to recover alongside the incubation period increase [16].

A number of publications have used $16 \mathrm{~S}$ rRNA amplicon sequencing to research the effects of tylosin on the soil microbial community [16], soil bacterial communities under the influence of manure and tetracycline [21], the effects of slurry from sulfadiazineand difloxacin-medicated pigs on the structural diversity of microorganisms in bulk and rhizosphere soil [22], and the soil bacterial community response to sulfadiazine in the soil-root zone [23].

Thus, the study of the replacement of several dominant bacterial species with others under the influence of antibacterial drugs can deepen the understanding of the ecological characteristics of the studied soil. The results obtained can be used in the development of approaches to preserve the natural structure of microbial communities and to ensure soil fertility. Consequently, the research objective was to study the microbial community dynamics and to identify their relation to the changes in catalase, urease, nitrification, and cellulolytic activities in the sod-podzolic soil cultivated in response to benzylpenicillin, oxytetracycline, and tylosin. As sod-podzolic soil is the main arable soil type of the Vladimir region and, alongside podzolic soil, accounts for up to $12.3 \%$ of the agricultural land and $14.7 \%$ of the arable land in Russia in general, its use in this research is of great practical importance [24].

\section{Results}

\subsection{Agrochemical Soil Indicators}

The agrochemical soil indicators are presented in Table 1. According to the results obtained, the studied soil is characterized by a weak acidity, medium humus content, low nitrate nitrogen content, and the absence of ammoniacal nitrogen, which is typical for this type of soil. A very high content of mobile forms of phosphorus and potassium has been established, which indicates a large amount of fertilizers applied. The object of this study is sod-podzolic medium loamy soil, which is the main type of arable soil in the Vladimir region and accounts for up to $12.3 \%$ of the agricultural land and $14.7 \%$ of the arable land in Russia [24].

Table 1. Agrochemical soil indicators.

\begin{tabular}{cc}
\hline Indicator, Unit & Value \\
\hline Acidity, $\mathrm{pH}_{\mathrm{KCl}}$ & $5.56 \pm 0.20$ \\
$\mathrm{P}_{2} \mathrm{O}_{5}$ mobile, $\mathrm{mg} / \mathrm{kg}$ & $436.5 \pm 87.30$ \\
$\mathrm{~K}_{2} \mathrm{O}$ mobile, $\mathrm{mg} / \mathrm{kg}$ & $275.6 \pm 41.34$ \\
Organic matter, $\%$ & $2.36 \pm 0.47$ \\
$\mathrm{~N}$ ammonium, $\mathrm{mg} / \mathrm{kg}$ & 0 \\
$\mathrm{~N}$ nitrates, $\mathrm{mg} / \mathrm{kg}$ & $10.1 \pm 1.52$ \\
Physical clay, $\%$ & 30.2 \\
\hline
\end{tabular}




\subsection{Determination of the Soil Enzymatic Activity}

The results of the soil enzymatic activity are shown in Figure 1. The amount of urease activity in the control was $0.951 \pm 0.031 \mathrm{mg} \mathrm{NH} / 10 \mathrm{~g}$ per $24 \mathrm{~h}$. All three antibiotics significantly reduced the urease activity of the soil. The Fisher test values were $\mathrm{F}=81.70$ $(p=0.00)$ for benzylpenicillin, $\mathrm{F}=62.98(p=0.00)$ for oxytetracycline, and $\mathrm{F}=119.32$ $(p=0.00)$ for tylosin. The nitrifying activity in the control was $996.65 \pm 35.84 \mathrm{mg} \mathrm{NO}_{3}{ }^{-} / \mathrm{kg}$. The introduction of antibiotics did not affect the nitrification. The Fisher test values were $\mathrm{F}=0.84(p=0.41)$ for benzylpenicillin, $\mathrm{F}=1.36(p=0.31)$ for oxytetracycline, and $\mathrm{F}=1.85$ $(p=0.25)$ for tylosin. Cellulolytic activity in the control was $47.35 \pm 2.11 \%$. A statistically significant increase was caused by benzylpenicillin $(\mathrm{F}=61.10, p=0.00)$ and oxytetracycline $(\mathrm{F}=11.31, p=0.02)$; tylosin had no effect on this indicator $(\mathrm{F}=1.60, p=0.25)$. The catalase activity in the control was $5.06 \pm 0.06 \mathrm{~mL} \mathrm{O}_{2} / \mathrm{min}$ per $1 \mathrm{~g}$. Benzylpenicillin increased the enzyme activity $(\mathrm{F}=69.11, p=0.00)$; no statistically significant effect of oxytetracycline $(\mathrm{F}=1.43, p=0.30)$ and tylosin $(\mathrm{F}=0.09, p=0.78)$ was found.

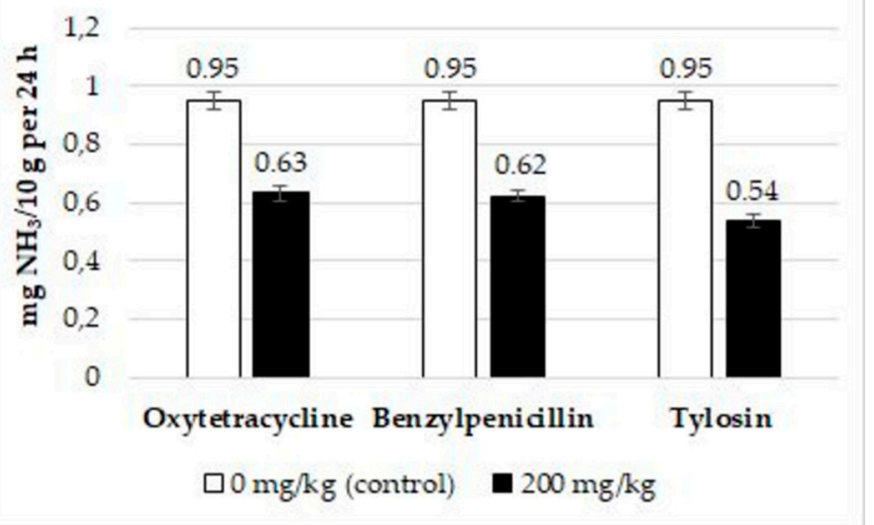

(a) Urease activity

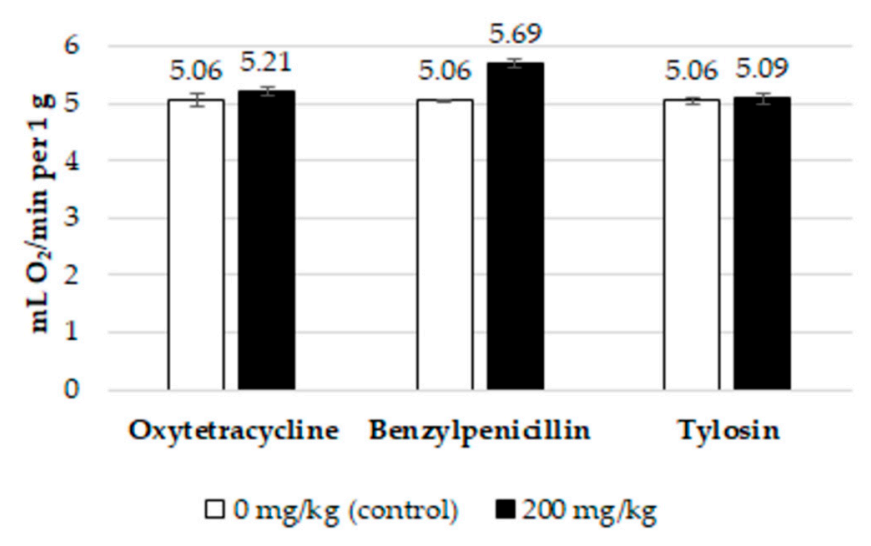

(c) Catalase activity

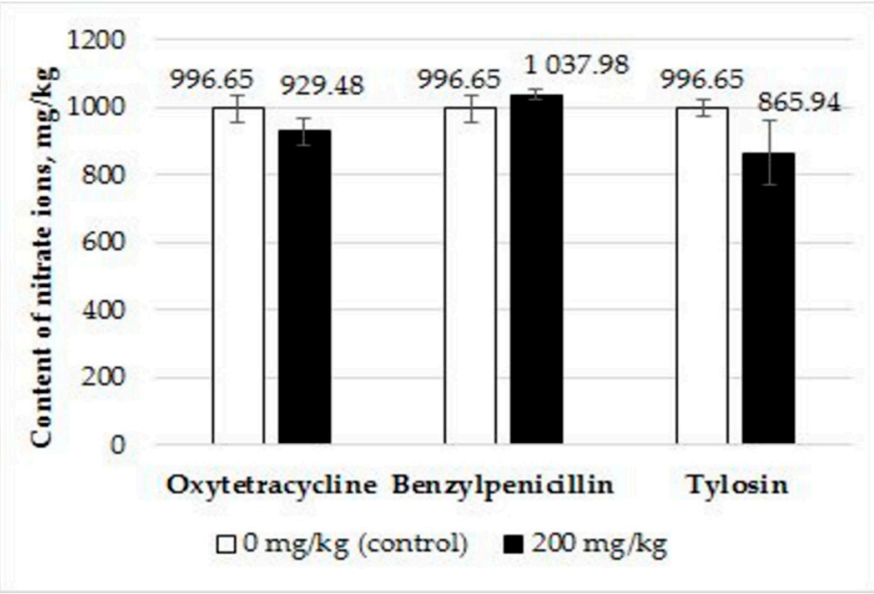

(b) Nitrification activity

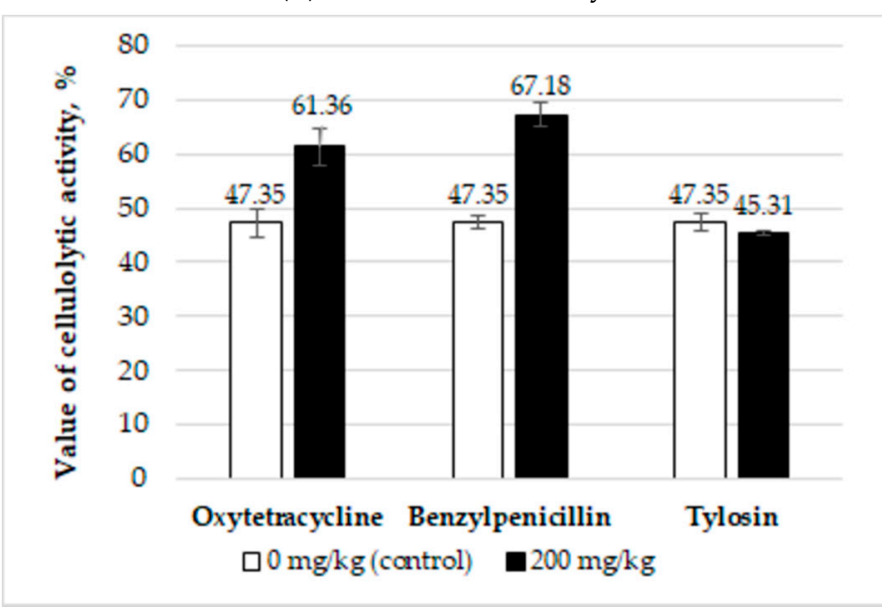

(d) Cellulolytic activity

Figure 1. The amount of soil enzymatic activity in the control $(0 \mathrm{mg} / \mathrm{kg})$ and with antibiotics $(200 \mathrm{mg} / \mathrm{kg})$ : (a) Urease activity, (b) Nitrification activity, (c) Catalase activity, (d) Cellulolytic activity.

\subsection{Metagenomic Sequencing}

The data processing resulted in 132,272 reads identified (30,000 reads per sample). After quality control and filtration, 3205, 3042, 3693, and 4500 nucleotide sequences were detected in samples 1, 3, 4, and 5, respectively, forming 201 operational taxonomic units (OTUs), 40 of which were unique (i.e., an OTU without any available information in the 
database). The numbers of OTUs per sample, as well as the Shannon, Simpson, and Chao1 indices, are shown in Table 2 and Figure S1.

Table 2. Alpha-diversity metrics.

\begin{tabular}{cccccc}
\hline Sample & OTU & Chao1 Index & Shannon Index & Simpson Index & Feit Phylogenetic Diversity \\
\hline 1 & 186 & 189.8 & 4.74 & 0.90 & 7.91 \\
3 & 191 & 199 & 5.21 & 0.95 & 7.77 \\
4 & 194 & 202 & 4.90 & 0.92 & 8.01 \\
5 & 197 & 201.9 & 4.49 & 0.88 & 7.92 \\
\hline
\end{tabular}

To quantify the proportion of the soil microbiome in each sample, the ratio of the detected OTUs to the Chao1 index was applied. The Chao1 index evaluates the theoretical number of species/OTUs in the studied microbiome. The population coverage amounted to over $95 \%$ of the theoretically calculated true microbiome diversity. The statistical analysis of the Chao1 index demonstrated the absence of significant diversity in the theoretical number of species/OTUs in the studied microbiome.

The Shannon diversity index in the four samples fluctuated from 4.49 to 5.21. This index characterizes the microbiome bacterial diversity. The higher the Shannon index, the greater the species diversity of the community. The results obtained indicated a high species diversity of communities in all studied samples. The statistical analysis demonstrated the absence of a significant variability in the taxonomic structure.

The Simpson index indicates the dominance of certain community members. When analyzing the samples, the dominance index varied from 0.88 to 0.95 . The obtained values of the Simpson index demonstrated a high diversity of prokaryotic communities in all studied samples. The statistical analysis indicated a uniform distribution without the predominance of any representatives.

The Feit phylogenetic diversity index was 7.7-8.0. This index is the sum of the lengths of the branches of the phylogenetic tree uniting all species of the studied sample and reflects the length of the evolutionary history in a given set of species. The statistical analysis demonstrated no significant changes in the microbial community structure in terms of the phylogenetic relation.

The Supplementary Materials contain Figure S1, which characterizes the dependence of the diversity of the microbiome in the form of detected OTUs on the selective effort (the number of sequenced nucleotide sequences). Figure S1 proves that, at 2000 reads per sample, the number of detected OTUs almost reached a plateau, which indicates the adequacy of the sampling effort in reflecting the theoretical diversity. The comparison of the change in the abundance of microbiota representatives by the grouped OTU are shown in Figure 2. Thus, Figure 2 shows the groups of bacteria in the control (sample 1) and those that survived after antibiotic treatment (samples 3-5).

The metagenomic 16S rRNA analysis showed that the samples contained Gramnegative bacteria such as the cyanobacteria genus Tychonema (o. Nostocales) and the bacteria genus Pseudomonas. The family Chitinophagaceae (o. Chitinophagales), containing genus Arthrobacter (o. Micrococcales), genus Massilia (o. Burkholderiales), genus Lysobacter, and genus Arenimonas (o. Xanthomonadales), was also present. Representatives of the archaea family Nitrososphaeraceae (o. Nitrososphaerales) were also present to the least extent. The dominant bacterium in samples 1, 3, and 4 was cyanobacterium genus Tychonema (o. Nostocales) whereas the dominant bacterium in sample 5 was genus Pseudomonas.

Figure 3 presents a thermal map of the difference between the bacterial abundance among the tested samples. For compactness, the OTUs are grouped according to the taxonomic order. 


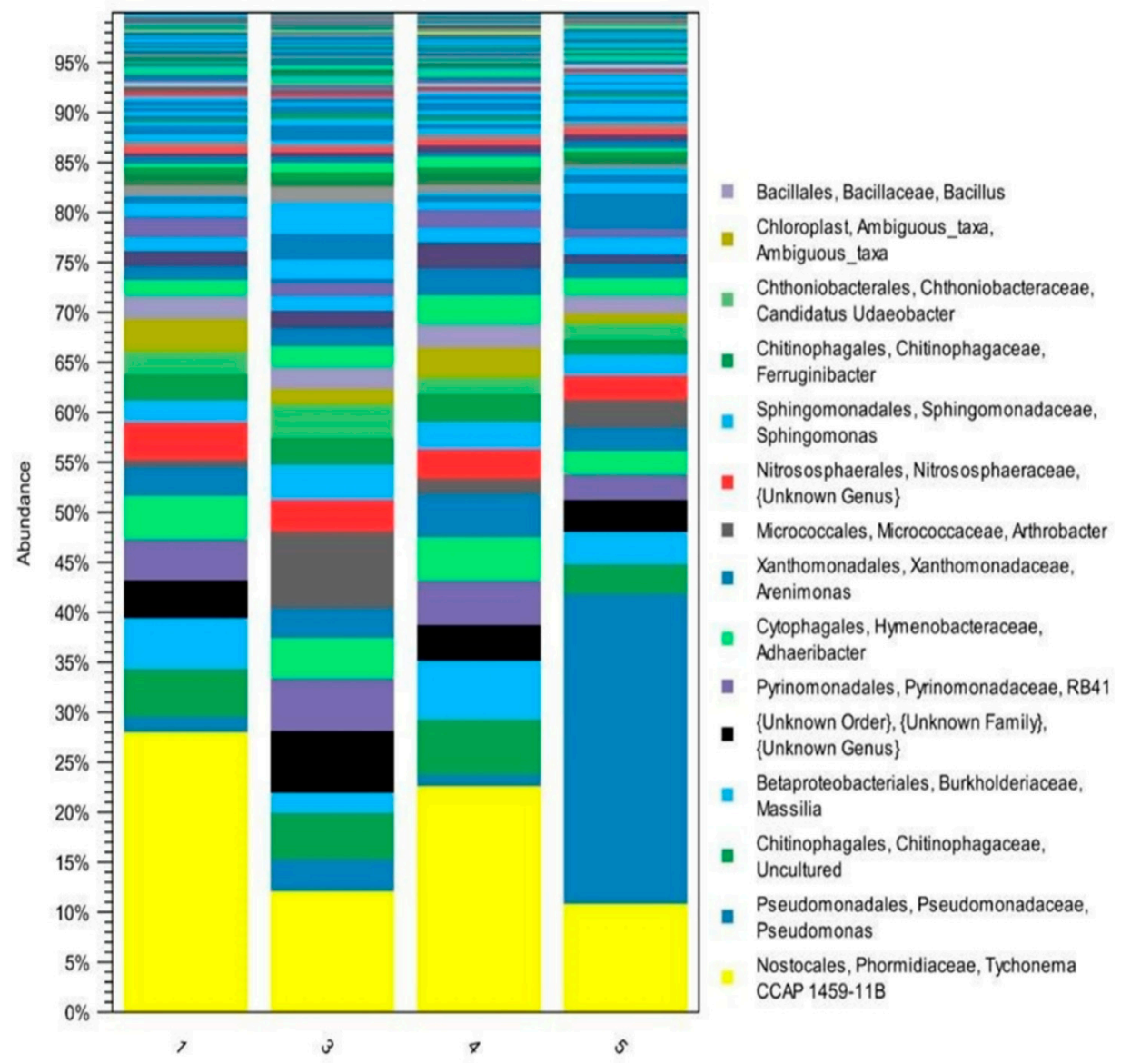

Figure 2. Graphical comparison of the bacterial abundance at the genus level for the studied samples.

Figure 3 shows that the abundance of certain representatives of the studied microbiomes varied depending on the antibacterial drug. Each specimen type possessed its own taxonomic abundance composition, phylogenetically related to each other. Despite the visible differences in Figures 2 and 3 in the structure of the microbiomes in the studied samples, no statistically significant changes occurred in the microbiome composition $(p>0.05)$.

The bacteria o. Nostocales (cyanobacteria), o. Frankiales, o. Gaielleles, o. Nitrososphaerales (archaea), and o. Opitutales dominated in the control. Sample 3 was characterized by the two groups consisting of bacteria Pyrinomonadales, Solibacteriales, Gemmatimonadales, and Microtrichiales and Chitinobacteriales, Streptomycetales, Sphingomonadales, Rhizobiales, Micrococcales, and Pseudonocardiales. The dominant bacteria for group 4 were Sphingobacteriales, Blastocatellales, Caulobacterales, Xanthomonadales, Chitinophagales, and Steroidobacteriales. The dominant composition for Group 5 consisted of Pseudomonadales, Gammaproteobacteria, Pedosphaerales, Bacillales, and Azospirillales.

Figure 4 shows the principal component analysis (PCoA) data of the control and antibiotic-treated samples.

The figure exhibits that the microbiome cluster of sample 5 (exposed to tylosin) differed from the control and samples 3 (benzylpenicillin) and 4 (oxytetracycline). It is important to note that no statistically significant changes occurred in the microbiome structure $(p>0.05)$. 


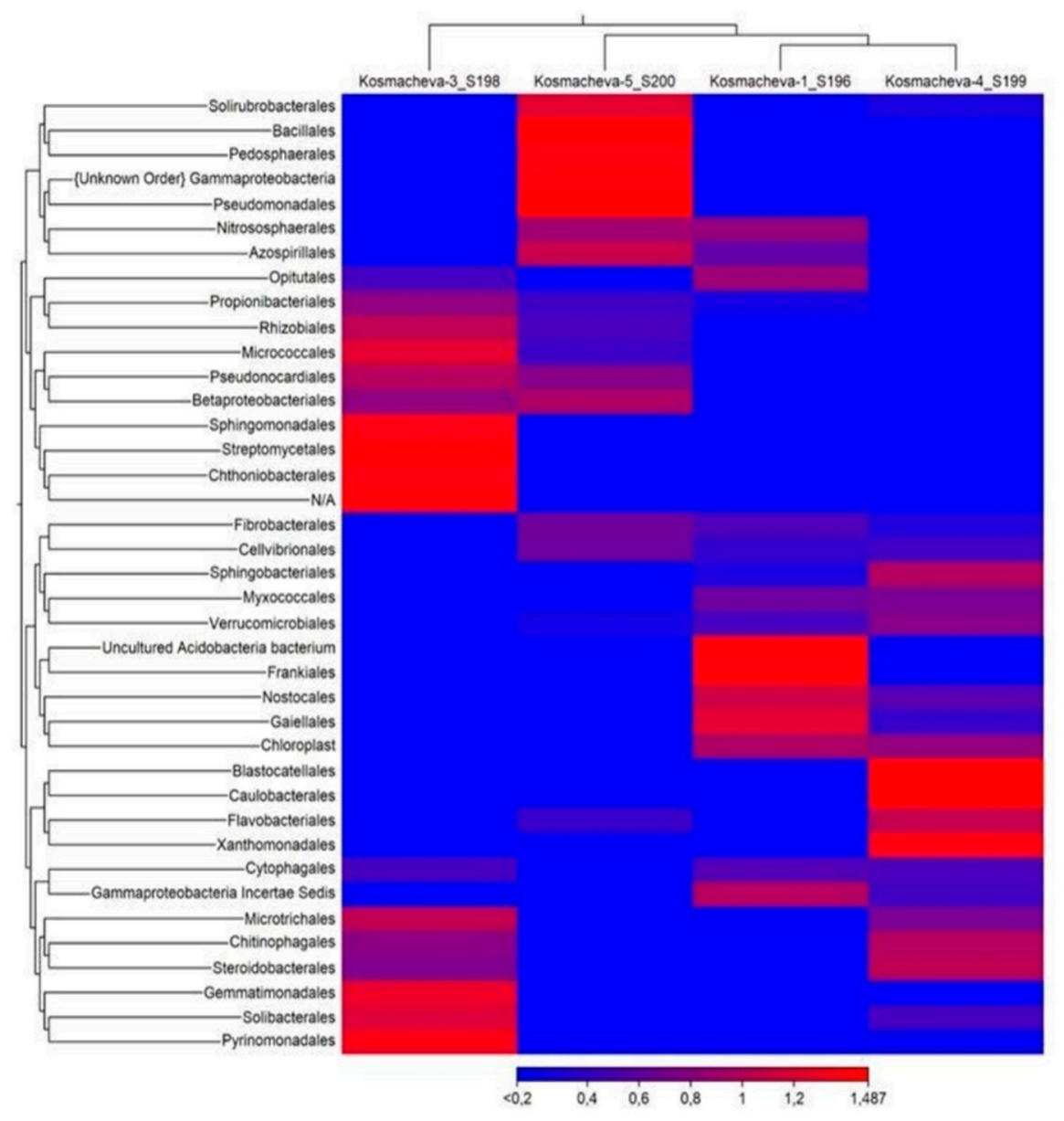

Figure 3. Thermal map of the bacteria abundance dynamics at the order level. The color bar indicates OTU relative abundances expressed as Z-scores.

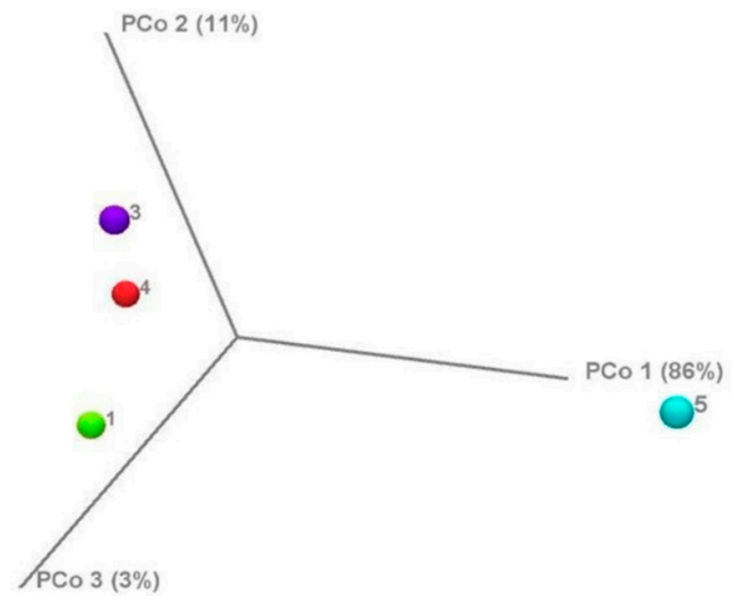

Figure 4. Principal component analysis (PCoA) showing the differences between the untreated (control) and antibiotic-treated soil samples determined using the weighted UniFrac diversity metric. Each colored symbol corresponds with an individual sample (1: untreated soil sample (control), 3: soil treated with benzylpenicillin, 4: soil treated with oxytetracycline, and 5: soil treated with tylosin). The variation represented by each axis (PC1, PC2, or PC3) is shown in parentheses.

\section{Discussion}

We believe that this research is the first metagenomic study conducted in the Russian Federation on the bacterial diversity of sod-podzolic soil in response to the impact of 
antibacterial drugs. This work is a continuation of previous studies. However, if-in previous works- the effect of antibiotics on enzymatic activity was studied, then this work focuses on the prokaryotic structure and its relationship with the enzymatic processes under the influence of antibiotics [17-20]. Several papers have been published concerning only the assessment of enzymatic activity dynamics without studying the microbiome and without determining the observed activity and, through it, soil fertility [11-13].

In this study, we evaluated enzymatic activity and changes in the soil microbiome in response to antibiotics.

The urease activity inhibition, when exposed to $200 \mathrm{mg} / \mathrm{kg}$ of oxytetracycline, was consistent with the results of a similar study [9] and the tylosin effect corresponded with previously published data dealing with this antibiotic effect on a different soil type $[17,18]$. Thus, all three antibiotics, differing in their properties and spectrum of action, were capable of suppressing the urease activity of the studied soil at the $200 \mathrm{mg} / \mathrm{kg}$ concentration. The urease activity inhibition is likely associated with changes in the archaea content of the Nitrososphaeraceae family, in which representatives can use urea as a substrate [25]. However, the content decrease in these microorganisms did not significantly affect the soil microbiome composition due to their low content (Figure 2).

The stimulating impact of benzylpenicillin detected on catalase activity can be explained by the bacterial increase with catalase activity regarding genus Arthrobacter (Figure 2) [26]. The obtained results were identical to similar data concerning a catalase activity increase under tylosin influence on chernozem and brown forest soils during the incubation of the contaminated samples and in dark chestnut soil at $1-100 \mathrm{mg} / \mathrm{kg}$ of the antibiotic in 3 days, which the authors associated with active enzyme production in response to the drug introduction [13].

The increase in cellulolytic activity under the influence of benzylpenicillin and oxytetracycline is likely explained by fungal enzymatic activity, which is not sensitive to these drugs, thus causing a fungal biomass increase in contrast to the bacterial biomass decrease under the influence of the antibiotics introduced. Moreover, the fungi killed by bacteria can be used as an additional energy source [16]. The insignificant inhibitory impact of tylosin on cellulolytic activity $(p>0.05)$ might depend on the additional substances in the drug composition enhancing its antiseptic effect in relation to both bacteria and fungi. Moreover, it was presumably associated with the established changes in the bacterial community composition regarding the bacterial predominance of the genus Pseudomonas (Figure 2) and the difference between this microbiome cluster and other samples (Figure 4). However, these indicators were also not statistically significant $(p>0.05)$.

The lack of an effect of the studied antibiotics on the soil nitrification activity can be explained by the spectrum of activity of the antibiotics. The nitrification process was carried out by Gram-negative bacteria and archaea [10]. The nitrification organisms in the studied soil were represented by the archaea of the Nitrososphaeraceae family although their contribution was negligible. The decrease in the nitrate ion content in the soil under tylosin impact can be explained by the increase in the number of bacteria from the genus Pseudomonas, which is involved in denitrification processes, in the microbiota composition [27]. Benzylpenicillin is effective against Gram-positive bacteria and, therefore, it cannot suppress nitrification microorganisms. The spectrum of oxytetracycline and tylosin action is wide; thus, it causes a reduction in nitrification activity. However, the dispersion analysis data revealed statistically significant differences in the nitrification activity neither in the control nor under the influence of these drugs $(p>0.05)$.

The bacterial community structures in the studied samples did not differ statistically significantly in terms of species diversity, the dominance of any taxon, or phylogenetic diversity $(p>0.05)$, thus demonstrating a certain resistance of soil communities in response to antibiotic exposure. The principle taxonomic groups of bacteria practically did not change $(p>0.05)$ but their abundance in the sample changed. Cyanobacteria (o. Nostocales) and genus Massilia (family Burkholderiaceae) predominated in these groups. Insignificant amounts of archaea were available in the control (sample 1 (untreated soil)) whereas they 
were not found in the experimental samples after antibiotic treatment. With a dominance of the genus Pseudomonas in sample 5 (Figure 2) in comparison with that in samples 1, 3, and 4 , the difference in microbiome cluster 5 (Figure 4) depended on the wide spectrum of tylosin action and the additional substances in the composition of the drug used (in particular, propylene glycol and benzyl alcohol), which possess antiseptic properties [28]. However, the difference between these indicators was statistically negligible $(p>0.05)$.

\section{Materials and Methods}

\subsection{Soil}

The sod-podzolic mid-loamy soil was selected in compliance with GOST 17.4.4.02-84 from an agricultural site in the Vladimir region, Russia $\left(56^{\circ} 14^{\prime} 47^{\prime \prime} \mathrm{N}, 40^{\circ} 34^{\prime} 51^{\prime \prime} \mathrm{E}\right)$, at 0-20 cm depth. The samples were taken using the envelope method from five points at the $1 \times 1 \mathrm{~m}$ site and thoroughly mixed. The sampled soil was air-dried at room temperature and sifted through a $2 \mathrm{~mm}$ sieve. Four homogeneously similar samples were taken from it, with one serving as the control (sample 1). Samples 3, 4, and 5 were treated by adding aqueous solutions of the antibiotics benzylpenicillin, oxytetracycline, and tylosin, respectively, at concentrations corresponding with $200 \mathrm{mg} / \mathrm{kg}$ of soil. Distilled water was used to prepare the antibiotic solutions. Before DNA isolation, the soil samples were stored in sterile plastic sealed containers at $-10{ }^{\circ} \mathrm{C}$ for three months.

\subsection{Determination of the Soil Agrochemical Characteristics}

The salt extract acidity $\left(\mathrm{pH}_{\mathrm{KCl}}\right)$ was determined using $1 \mathrm{M}$ solution of potassium chloride in the soil and a solution ratio of 1:2.5 following the potentiometric method.

The organic matter content was determined following the photoelectrocolorimetric method using a photometer KFK-3-01 based on the organic matter oxidation with a potassium dichromate solution in sulfuric acid and the subsequent determination of trivalent chromium equivalent to the organic matter content.

The physical clay content (granulometric composition) was determined using the mass content of various sizes expressed as a percentage relative to the mass of the dry soil sample taken for the analysis.

Nitrates were extracted from the soil with an aluminum-potassium alum solution with $1 \%$ mass fraction at the ratio of soil sample mass to the solution volume of 1:2.5 and with the subsequent determination of the nitrates in the extract using an ion-selective electrode (Expert-001, Econix-Expert, Rumyantsevo, Russia).

Exchange ammonium was extracted from the soil with a potassium chloride solution to obtain a colored indophenol compound formed via the interaction of ammonium with hypochlorite and sodium salicylate in an alkaline medium and the subsequent photometry of the colored solution using a photometer KFK-3-01.

The mobile potassium $\left(\mathrm{K}_{2} \mathrm{O}\right)$ and phosphorus $\left(\mathrm{P}_{2} \mathrm{O}_{5}\right)$ compounds were extracted from the soil using a hydrochloric acid solution of $0.2 \mathrm{~mol} / \mathrm{dm}^{3} \mathrm{molar}$ concentration and determined using a KFK-3-01 photometer.

\subsection{Antibiotics}

Tylosin, referred to as the macrolides group, was used in the drug formulation of the injectable solution with an active substance concentration of $200 \mathrm{mg} / \mathrm{cm}^{3}$. The antibiotic produces a bacteriostatic effect and has the potential for time-dependent bactericidal action.

Oxytetracycline, referred to as the tetracyclines group, was used in the oxytetracycline hydrochloride composition. The drug is characterized by a wide spectrum of activity against Gram-positive and Gram-negative bacteria. In most cases, it exhibits a bacteriostatic effect.

Benzylpenicillin, referred to as the $\beta$-lactam antibiotic group, was used in the composition of benzylpenicillin sodium salt. It exhibits bactericidal and bacteriostatic effects and is efficacious against Gram-positive organisms [29]. 
The process antibiotic solutions were prepared by diluting the initial preparations in distilled water. The studied concentrations $(200 \mathrm{mg} / \mathrm{kg}$ of soil) were selected based on the published data [9-13] and our research results concerning changes in the soil enzymatic activity under the impact of a wide range of antibiotic concentrations [17-20].

\subsection{Enzymatic Activity Determination}

The soil enzymatic activity was determined in model laboratory experiments.

The soil cellulolytic activity was determined using the modified Christensen application method based on the calculation of decomposed cellulose. One cotton cloth piece of size $3 \times 4 \mathrm{~cm}^{2}$, serving as a source of fiber, previously kept in a drying cabinet at $105{ }^{\circ} \mathrm{C}$ for $2 \mathrm{~h}$, and weighed to $0.0001 \mathrm{~g}$ accuracy, was placed at the bottom of each sterile Petri dish. Afterwards, $50 \mathrm{~g}$ of the test soil, moistened to $60 \%$ of the total moisture capacity and contaminated with antibiotic solutions, was added into each Petri dish. The Petri dishes were weighed, placed into the thermostat, and incubated at $27^{\circ} \mathrm{C}$ for 30 days. The soil was moistened daily with distilled water. In 30 days, the remaining cloth was removed from the Petri dishes, cleaned from the soil, dried at $105^{\circ} \mathrm{C}$, and weighed to $0.0001 \mathrm{~g}$ accuracy. The difference in the cloth mass (\%) decomposed during the experiment served as the soil cellulolytic activity indicator [30].

The catalase activity was determined by applying the gasometric method to determine the rate of hydrogen peroxide decomposition in the soil by the volume of oxygen released during the reaction. For this purpose, the $1 \mathrm{~g}$ soil samples, moistened up to $60 \%$ of the total moisture capacity and contaminated with antibiotics, were exposed at a temperature of $22{ }^{\circ} \mathrm{C}$ for 5 days. The control was the original soil without any drug introduction. Furthermore, a $1 \mathrm{~g}$ soil lot was placed in a flask, $0.5 \mathrm{~g}$ calcium carbonate was added and attached to the system for the gasometric determination of the catalase activity, $5 \mathrm{~mL}$ of a $3 \%$ hydrogen peroxide solution was added, and the released oxygen volume was measured for 1 min at constant stirring in an orbital shaker [31].

The soil urease activity was determined by applying the photocolorimetric method by counting the amount of ammonia formed during the hydrolysis of the introduced urea. For this purpose, $1 \mathrm{~g}$ of soil was placed in a flask and $5 \mathrm{~mL}$ of a $3 \%$ urea solution and 1 drop of toluene were added. The flasks were sealed with cork stoppers, shaken, and exposed in a thermostat at $30{ }^{\circ} \mathrm{C}$ for $24 \mathrm{~h}$. After the incubation period, $15 \mathrm{~mL}$ of $1.0 \mathrm{n}$. $\mathrm{KCl}$ solution was added into each flask and stirred in an orbital shaker for $5 \mathrm{~min}$. Afterwards, $10 \mathrm{~mL}$ of the soil extract was transferred into a centrifuge tube and centrifuged for $5 \mathrm{~min}$ at $3000 \times \mathrm{rpm}$. An amount of $1 \mathrm{~mL}$ of the centrifugate was placed in a $50 \mathrm{~mL}$ measuring flask and $30 \mathrm{~mL}$ of distilled water, $2 \mathrm{~mL}$ of a 30\% solution of potassium-sodium tartaric acid, and $2 \mathrm{~mL}$ of a Nessler chemical agent were added. After each addition, the solution was stirred, reaching the desired volume by adding distilled water, and was thoroughly mixed and colorimetrated in a KFK-3-01 photometer in $30 \mathrm{~mm}$ wide cuvettes with a blue light filter at a $400 \mathrm{~nm}$ wavelength. Urease activity was expressed in milligrams of $\mathrm{NH}_{3}$ per $10 \mathrm{~g}$ of soil per day [32].

To determine the nitrification activity, $100 \mathrm{~g}$ of soil was placed into a sterile conical flask and moistened with distilled water up to $65 \%$ of the total moisture capacity by adding the solutions of the appropriate antibiotics. A total of $0.1 \mathrm{~g}$ of ammonium sulfate and $0.2 \mathrm{~g}$ of calcium carbonate were added into each suspension, covered with a cotton plug, and incubated in a Sanyo MLR-351 climate chamber for 30 days at a constant temperature of $27{ }^{\circ} \mathrm{C}$ in the dark. The soil moisture was maintained by the addition of distilled water weekly to reach its initial level. To assess the nitrification activity, the nitrate ion content in the samples was measured after the incubation period: the soil from each flask was placed into Petri dishes, air-dried at $40{ }^{\circ} \mathrm{C}$, and thoroughly mixed; $20 \mathrm{~g}$ was taken from each sample and $50 \mathrm{~mL}$ of a $1 \%$ aluminum-potassium alum solution was added and mixed by the orbital shaker for $20 \mathrm{~min}$. The nitrate ion content in the samples was determined and measured by applying the potentiometric method (Expert-001, Econix-Expert, Rumyantsevo, Russia). To assess the antibiotic effect on the soil nitrification activity, the results of the nitrate ion 
content in the sample that did not contain antibiotics (value 0 in the graphs) were compared with the value when the corresponding antibiotics were added [32].

The catalase, urease, and nitrification activities were determined in triple replication and cellulolytic activity was determined four-fold. The initial soil without the introduction of antibiotics was considered to be the control.

\subsection{Statistics Analysis}

The results were statistically processed using Statistica 7.0 software. To statistically analyze the effect of the antibiotic concentration on enzymatic activity, a single-factor analysis of variance was used including a Fisher F-test determination (significance level: $p<0.05)$. The standard error values were indicated as the error. The graphs were plotted in Microsoft Excel.

Alpha- and beta-analyses of the biodiversity among the OTU frequencies were performed using a CLC Genomics Workbench (Qiagen, Hilden, Germany) with default parameters. The alpha-diversity was evaluated using the Shannon diversity index, providing estimations of the diversity species; the phylogenetic diversity index, demonstrating the taxa affinity degree represented in the compared communities; the Chao1 index, estimating the total number of taxa in a community; and the Simpson index, demonstrating the probability of two individuals being randomly selected from the indefinitely large community of different taxa. The Kruskal-Wallis test was used to assess the statistical significance among the groups.

To estimate the beta-diversity, the "weighted unifrac" method was applied, allowing for the estimation of the percentage of similarities/differences among the samples, taking into account the phylogenetic information. The results were presented using the multivariate statistics methods of the PCoA analysis. The data visualization was performed in the CLC Genomics Workbench program.

\subsection{DNA Preparation for Sequencing}

A set of NucleoSpin Soil chemicals (Macherey-Nagel, Düren, Germany) was used to isolate the DNA from the soil samples. The v3-v4 region of the 16S rRNA gene was used as the target amplification site [33].

A PCR with an F515 direct primer and an R806 reverse primer was performed in a $15 \mu \mathrm{L}$ reaction mixture containing a $0.5-1$ activity unit of Q $5^{\circledR}$ High-Fidelity DNA Polymerase (NEB, Ipswich, MA, USA), 5 pcM of direct and reverse primers, 10 ng of a DNA matrix, and $2 \mathrm{nM}$ of each dNTP (LifeTechnologies, Foster City, CA, USA). The mixture was denatured at $94{ }^{\circ} \mathrm{C}$ for $1 \mathrm{~min}$, followed by 35 cycles: $94{ }^{\circ} \mathrm{C}$ for $30 \mathrm{~s}, 50^{\circ} \mathrm{C}$ for $30 \mathrm{~s}$, and $72{ }^{\circ} \mathrm{C}$ for $30 \mathrm{~s}$. The final elongation occurred at $72{ }^{\circ} \mathrm{C}$ for $3 \mathrm{~min}$. The PCR products were purified using AMPureXP (BeckmanCoulter, Chaska, MN USA). Further library preparations were carried out in accordance with the manufacturer's MiSeq Reagent Kit Preparation Guide (Illumina San Diego, CA, USA).

\subsection{Sequencing}

The amplicon library analysis of the ribosomal operon fragments by high-performance $16 \mathrm{~S}$ rRNA gene sequencing was performed using an Illumina MiSeq system (Illumina, USA) and a MiSeq ${ }^{\circledR}$ ReagentKit v3 (600 cycle) reagent kit with a double-row reading $(2 \times 300 \mathrm{n})$. The data received after the sample sequencing were processed using CLC Genomics "Workbench" software. Clustering into the OTU and annotation were performed according to the SILVA 16S v132 99\% database, a part of the Microbial Genomics Module. The reading quality analysis, pair-end sequence integration, and chimera removal were performed using the Microbial Genomics Module with default parameters. The OTU was grouped according to the level of taxonomic similarity at a threshold of $97 \%$ and the total occurrence reliability was at least 10 OTUs per analyzed group of samples.

The results were obtained using the equipment from CCP "Genomic Technologies, Proteomics, and Cell Biology" of FGBNU VNIISKHM. 


\section{Conclusions}

The combination of $16 \mathrm{~S}$ rRNA amplicon sequencing methods with classic methods for studying the enzymatic activity of soils is an important way to solve problems in the ecology of soil microorganisms concerning the relationship between the structure of microbial communities and ongoing biogeochemical processes. Despite a rapid growth in the number of metagenomic studies, this article is the first publication devoted to the microbial diversity of sod-podzolic soil and its relationship with enzymatic activity. As the soil microbiome is characterized by a richness of species diversity, the continuation of such studies is required, including a more complete study of the effects of a wide range of antibacterial drugs comprising not only the prokaryotic pool but also soil fungi. Metagenomic profiling by $16 \mathrm{~S}$ rRNA revealed the dominance of Gram-negative bacteria in the genus Tychonema in the soil without antibiotic exposure, which remained under the treatment with benzylpenicillin and oxytetracycline. However, when treated with tylosin, the microbiome composition shifted towards the dominance of the Pseudomonas genus. Despite the detected resistance of the microbial community of the studied soil in response to benzylpenicillin, oxytetracycline, and tylosin, changes in the soil enzymatic processes were observed depending both on the enzymatic activity type and on the drugs used. Thus, antibiotic introduction might negatively impact the enzymatic processes of soils without a significant influence on the microbial community structure.

Supplementary Materials: The following are available online at https:/ /www.mdpi.com/article/ 10.3390/antibiotics10080970/s1, Figure S1: The ratio curve between the bacterial community diversity at the genus level and selective effort. 1: untreated soil sample (control); 3: soil treated with benzylpenicillin; 4: soil treated with oxytetracycline; and 5: soil treated with tylosin.

Author Contributions: Conceptualization, T.T. and A.K.; methodology, S.C. and A.S.; software, A.S. and O.B.; validation, T.T.; formal analysis, A.K. and A.S.; investigation, T.T., A.K. and A.S.; resources, T.T., A.S. and O.B.; data curation, T.T. and S.C.; writing-original draft preparation, A.K. and A.S.; writing—review and editing, T.T.; visualization, A.K. and A.S.; supervision, T.T.; project administration, T.T. All authors have read and agreed to the published version of the manuscript.

Funding: This research received no external funding.

Institutional Review Board Statement: Not applicable.

Informed Consent Statement: Not applicable.

Data Availability Statement: All reported findings are available within the manuscript.

Acknowledgments: This research was performed according to the Development program of the Interdisciplinary Scientific and Educational School of M.V. Lomonosov Moscow State University "Future Planet and Global Environmental Change".

Conflicts of Interest: The authors declare no conflict of interest.

\section{References}

1. Rasschaert, G.; Van Elst, D.; Colson, L.; Herman, L.; Ferreira, H.C.D.C.; Dewulf, J.; Decrop, J.; Meirlaen, J.; Heyndrickx, M.; Daeseleire, A.E. Antibiotic Residues and Antibiotic-Resistant Bacteria in Pig Slurry Used to Fertilize Agricultural Fields. Antibiotics 2020, 9, 34. [CrossRef]

2. Huygens, J.; Daeseleire, E.; Mahillon, J.; Van Elst, D.; Decrop, J.; Meirlaen, J.; Dewulf, J.; Heyndrickx, M.; Rasschaert, G. Presence of Antibiotic Residues and Antibiotic Resistant Bacteria in Cattle Manure Intended for Fertilization of Agricultural Fields: A One Health Perspective. Antibiotics 2021, 10, 410. [CrossRef] [PubMed]

3. Mdegela, R.H.; Mwakapeje, E.R.; Rubegwa, B.; Gebeyehu, D.T.; Niyigena, S.; Msambichaka, V.; Nonga, H.E.; Antoine-Moussiaux, N.; Fasina, F.O. Antimicrobial Use, Residues, Resistance and Governance in the Food and Agriculture Sectors, Tanzania. Antibiotics 2021, 10, 454. [CrossRef]

4. Kaczala, F.; Blum, S.E. The Occurrence of Veterinary Pharmaceuticals in the Environment: A Review. Curr. Anal. Chem. 2016, 12, 169-182. [CrossRef] [PubMed]

5. Grenni, P.; Ancona, V.; Caracciolo, A.B. Ecological effects of antibiotics on natural ecosystems: A review. Microchem. J. 2018, 136, 25-39. [CrossRef]

6. Daniel, R. The Metagenomics of Soil. Nat. Rev. Microbiol. 2005, 3, 470-478. [CrossRef] 
7. Cycoń, M.; Mrozik, A.; Piotrowska-Seget, Z. Antibiotics in the Soil Environment-Degradation and Their Impact on Microbial Activity and Diversity. Front. Microbiol. 2019, 10, 338. [CrossRef] [PubMed]

8. van de Vijver, L.; Verwer, C.; Smolders, G.; Hospers-Brands, M.; van Eekeren, N. The Cycle of Veterinary Antibiotics in the Ecosystem; Louis Bolk Instituut: Driebergen, The Netherlands, 2016; p. 31.

9. Chen, W.; Liu, W.; Pan, N.; Jiao, W.; Wang, M. Oxytetracycline on functions and structure of soil microbial community. J. Soil Sci. Plant Nutr. 2013, 13, 967-975. [CrossRef]

10. Roose-Amsaleg, C.; Laverman, A.M. Do antibiotics have environmental side-effects? Impact of synthetic antibiotics on biogeochemical processes. Environ. Sci. Pollut. Res. 2016, 23, 4000-4012. [CrossRef] [PubMed]

11. Akimenko, Y.V.; Kazeev, K.S.; Kolesnikov, S.I. Ecological Consequences of Chernozem Contamination with Antibiotics: Monograph; Southern Federal University Press: Rostov-on-Don, Russia, 2013; p. 120. ISBN 978-5-9275-1185-3. (In Russian)

12. Akimenko, Y.V.; Kazeev, K.S.; Kolesnikov, S.I. The Antibiotic Contamination Influence on the Biological Properties of Ordinary Chernozem: Monograph; Southern Federal University Press: Rostov-on-Don, Russia, 2015; p. 154. ISBN 978-5-9275-1797-8. (In Russian)

13. Akimenko, Y.V.; Chuvaraeva, O.V.; Kolesnikov, S.I.; Kazeev, K.S.; Minnikova, T.V. Assessment of the Ecological State of the Basic Soils of the Southern Russia under the Contamination Conditions with Antibiotics: Monograph; Southern Federal University Press: Rostov-on-Don, Russia, 2019; p. 114. ISBN 978-5-9275-3247-6. (In Russian)

14. Schmitt, H. The Effects of Veterinary Antibiotics on Soil Microbial Communities. Ph.D. Thesis, Universiteit Utrecht, Utrecht, The Netherlands, 2005; p. 195.

15. Wang, X.; Pan, H.; Gu, J.; Qian, X.; Gao, H.; Qin, Q. Effects of oxytetracycline on archaeal community, and tetracycline resistance genes in the anaerobic co-digestion of pig manure and wheat straw. Environ. Technol. 2016, 37, 3177-3185. [CrossRef] [PubMed]

16. Westergaard, K.; Müller, A.K.; Christensen, S.; Bloem, J.; Sørensen, S.J. Effects of tylosin as a disturbance on the soil microbial community. Soil Biol. Biochem. 2001, 33, 2061-2071. [CrossRef]

17. Trifonova, T.A.; Chesnokova, S.M.; Kosmacheva, A.G. Evaluation of ampicillin and tylosin antibiotics effect on the enzymatic activity of sod-podzolic soil and their toxicity for cultivated plants. Theor. Appl. Ecol. 2020, 2, 150-156. (In Russian) [CrossRef]

18. Trifonova, T.A.; Chesnokova, S.M.; Kosmacheva, A.G. Impact study of antibiotics of various groups on the cellulolytic activity of sod-podzolic soil by laboratory modeling. Agrochemistry 2020, 10, 72-78. (In Russian) [CrossRef]

19. Kosmacheva, A.G. Assessment of the impact of the antibiotics benzylpenicillin, oxytetracycline and tylosin on catalase activity of weakly loamy sod-podzolic and gray forest soils. Grani Pozn. 2019, 6, 79-83. (In Russian)

20. Kosmacheva, A.G.; Chesnokova, S.M.; Trifonova, T.A. Study of the Effect of Antibiotics of Various Groups on the Nitrification Activity of Sod-podzolic Soil by the Method of Laboratory Modelling. Izv. Saratov Univ. Series Chem. Biol. Ecol. 2020, 3, 352-358. [CrossRef]

21. Chessa, L.; Jechalke, S.; Ding, G.-C.; Pusino, A.; Mangia, N.P.; Smalla, K. The presence of tetracycline in cow manure changes the impact of repeated manure application on soil bacterial communities. Biol. Fertil. Soils 2016, 52, 1121-1134. [CrossRef]

22. Reichel, R.; Rosendahl, I.; Peeters, E.T.H.M.; Focks, A.; Groeneweg, J.; Bierl, R.; Schlichting, A.; Amelung, W.; Thiele-Bruhn, S. Effects of slurry from sulfadiazine- (SDZ) and difloxacin- (DIF) medicated pigs on the structural diversity of microorganisms in bulk and rhizosphere soil. Soil Biol. Biochem. 2013, 62, 82-91. [CrossRef]

23. Reichel, R.; Michelini, L.; Ghisi, R.; Thiele-Bruhn, S. Soil bacterial community response to sulfadiazine in the soil-root zone. J. Plant Nutr. Soil Sci. 2015, 178, 499-506. [CrossRef]

24. Soil Sci Inst., Moscow. Unified State Register of Soil Resources of Russia. Version 1.0. 2014. (In Russian). Available online: http:/ / egrpr.esoil.ru/ (accessed on 2 May 2021).

25. Yang, Y.; Herbold, C.W.; Jung, M.-Y.; Qin, W.; Cai, M.; Du, H.; Lin, J.-G.; Li, X.; Li, M.; Gu, J.-D. Survival strategies of ammonia-oxidizing archaea (AOA) in a full-scale WWTP treating mixed landfill leachate containing copper ions and operating at low-intensity of aeration. Water Res. 2021, 191, 116798. [CrossRef]

26. Zhang, J.; Ma, Y.; Yu, H. Arthrobacter cupressi sp. nov., an actinomycete isolated from the rhizosphere soil of Cupressus sempervirens. Int. J. Syst. Evol. Microbiol. 2012, 62, 2731-2736. [CrossRef]

27. Umarov, M.M.; Kurakov, A.V.; Stepanov, A.L. Microbial Transformation of Nitrogen in Soil; GEOS: Moscow, Russia, 2007; p. 138, ISBN 5-89118-315-7. (In Russian)

28. Anderson, B.; de Peyster, A.; Gad, S.C.; Hakkinen, P.J.B.; Kamrin, M.; Locey, B.; Mehendale, H.M.; Pope, C.; Shugart, L.P.; Wexler, P. Encyclopedia of Toxicology, Four-Volume Set: Encyclopedia of Toxicology, 2nd ed.; Academic Press: Cambridge, MA, USA, 2005; Volume 1, p. 794.

29. Riviere, J.; Lees, P.; Elliott, J.; Clarke, C.; Anadón, A.; Baggot, D.; Brown, S.A.; Burka, J.F.; Clarke, C.R.; Craigmill, A.; et al. USP Veterinary Pharmaceutical Information Monographs_Antibiotics. J. Vet. Pharmacol. Ther. 2003, 26, 1-271. [CrossRef] [PubMed]

30. Voznyakovskaya, Y.M. (Ed.) Principle Microbiological and Biochemical Methods of Soil Research: Method, Recommendations; VNIISKHM: Leningrad, Russia, 1987; p. 47. (In Russian)

31. Khaziev, F.K. Methods of Soil Enzymology; Nauka: Moscow, Russia, 2005; p. 252. ISBN 5-02-033940-7. (In Russian)

32. Kazeev, K.S.; Kolesnikov, S.I.; Valkov, V.F. Biological Diagnostic and Indication of Soils: The Methodology and Methods of Research; Publishing House of Rostov University: Rostov-on-Don, Russia, 2003; p. 216. (In Russian)

33. Bates, S.T.; Berg-Lyons, D.; Caporaso, J.G.; Walters, W.A.; Knight, R.; Fierer, N. Examining the global distribution of dominant archaeal populations in soil. ISME J. 2011, 5, 908-917. [CrossRef] [PubMed] 